\title{
REGIONAL CEREBRAL BLOOD FLOW DURING REWARMING OF CARDIOPULMONARY BYPASS CORRELATES WITH POSTHYPOTHERMIC REGIONAL GLUCOSE USE
}

Hiroshi Miyano, $\mathrm{MD}^{\mathrm{a}}$

Michihito Inagaki, $\mathrm{PhD}^{\mathrm{b}}$

Naoto Hashimoto, $\mathrm{PhD}^{\mathrm{b}}$

Toshiaki Shishido, MD ${ }^{\mathrm{a}}$

Toru Kawada, PhD, $\mathrm{MD}^{\mathrm{a}}$

Yoshihiro Miyake, $\mathrm{PhD}^{\mathrm{b}}$

Kenji Sunagawa, PhD, MD
Background and objectives: Although global measurements of cerebral blood flow and metabolism during and after profoundly hypothermic cardiopulmonary bypass have been performed both in experimental animals and in human beings, little is known about their regional changes. The purpose of this study was to investigate the changes in regional cerebral blood flow during profoundly hypothermic cardiopulmonary bypass and regional cerebral glucose use after cardiopulmonary bypass. Methods: We measured regional cerebral blood flow with positron emission tomography during both the cooling $(n=5)$ and rewarming $(n=5)$ of hypothermic cardiopulmonary bypass in anesthetized dogs by continuously infusing ${ }^{15} \mathrm{O}$ labeled water. We altered the core temperature between $20^{\circ}$ and $37^{\circ} \mathrm{C}$. To assess the integrity of brain metabolism, we measured the regional cerebral glucose use by bolus injections of ${ }^{18} \mathrm{~F}$-labeled 2 -fluoro-2-deoxy-D-glucose. Results: Regional cerebral blood flow decreased homogeneously during cooling. The regional cerebral blood flow at $20^{\circ} \mathrm{C}$ was about one fourth of that at $37^{\circ} \mathrm{C}$. In contrast, at $24^{\circ}, 28^{\circ}$, and $32^{\circ} \mathrm{C}$ during rewarming, there were significant interregional differences in the regional cerebral blood flow for given temperatures $(p=0.0075,0.034$, and 0.048 , respectively). These interregional differences disappeared after rewarming. Although the regional cerebral blood flow significantly correlated with the regional cerebral glucose use in the control condition at $37^{\circ} \mathrm{C}$ without cardiopulmonary bypass $(r=0.75 ; p=0.00012)$, this correlation disappeared after profoundly hypothermic cardiopulmonary bypass $(r=0.204 ; p=0.388$ ). Regional cerebral blood flow at $32^{\circ} \mathrm{C}$ during rewarming positively correlated with the regional cerebral glucose use after cardiopulmonary bypass $(r=0.655 ; p=0.0017)$. Conclusion: The altered regional cerebral blood flow during rewarming of profoundly hypothermic cardiopulmonary bypass might affect regional brain metabolism. (J Thorac Cardiovasc Surg 1998; 116:503-10)
P ostoperative brain damage remains one of the major complications after profoundly hypothermic cardiopulmonary bypass (CPB).$^{1-3}$ Various investigators have ascribed it to the prolonged cere-

From the Department of Cardiovascular Dynamics, National Cardiovascular Center Research Institute, ${ }^{\text {a }}$ and the Institute for Biofunctional Research, ${ }^{\mathrm{b}}$ Osaka, Japan.

Received for publication June 4, 1997; revisions requested August 8, 1997; revisions received Feb. 27, 1998; accepted for publication Feb. 27, 1998.

Address for reprints: Hiroshi Miyano, MD, Department of Cardiovascular Dynamics, National Cardiovascular Center Research Institute, 5-7-1 Fujishirodai, Suita, Osaka 565, Japan.

Copyright (C) 1998 by Mosby, Inc.

$0022-5223 / 98 \$ 5.00+0 \quad \mathbf{1 2 / 1 / 9 0 0 1 6}$ bral hypoperfusion ${ }^{3}$ and/or the embolization of air, fat, or particulate materials derived from aortic atheroma. $^{3-7}$ Global changes in cerebral blood flow (CBF) and cerebral oxygen use $\left(\mathrm{CMRO}_{2}\right)$ after profoundly hypothermic CPB have been investigated in human beings ${ }^{8}$ and in experimental ani. mals. ${ }^{9,10}$ However, how regional cerebral blood flow (rCBF) and metabolism change during and after profoundly hypothermic CPB remain unknown.

Recent development of positron emission tomography (PET) has made it possible to accurately measure regional cerebral metabolism both in experimental and in clinical settings. In particular, the use of PET to measure rCBF with ${ }^{15} \mathrm{O}$-labeled water, regional cerebral glucose use $\left(\mathrm{rCMR}_{\text {gic }}\right)$ with ${ }^{18}$ F-labeled 2-fluoro-2-deoxy-D-glucose ( $\left.{ }^{18} \mathrm{FDG}\right)$, and 
regional $\mathrm{CMRO}_{2}\left(\mathrm{rCMRO}_{2}\right)$ with ${ }^{15} \mathrm{O}$-labeled carbon dioxide has been well established. ${ }^{11}$ Because it allows repetitive measurements, PET is particularly useful in studying how hypothermic CPB affects brain perfusion and metabolism. To investigate the mechanism by which hypothermic $\mathrm{CPB}$ damages the brain, we measured rCBF using PET during the cooling and rewarming of profoundly hypothermic $\mathrm{CPB}$ at $20^{\circ} \mathrm{C}$, which has often been used for complex aortic arch repair with the combination of circulatory arrest or retrograde cerebral perfusion. ${ }^{12}$ To evaluate the ischemic damage and the integrity of brain metabolism, we measured $\mathrm{rCMR}_{\mathrm{glc}}$.

\section{Materials and methods}

Animal preparation. All animals involved in this study received humane care in compliance with the "Guiding Principles in the Care and Use of Animals" approved by the Council of American Physiological Society (revised in 1980) and the "Guide for the Care and Use of Laboratory Animals" published by the National Institutes of Health (NIH publication No. 85-23, revised in 1985).

Fifteen mongrel dogs, weighing between 14 and $20 \mathrm{~kg}$, were used in this study. We conducted hypothermic CPB in $10 \mathrm{dogs}$; the other five dogs served as controls without CPB. Anesthesia was induced with ketamine hydrochloride ( $5 \mathrm{mg} \cdot \mathrm{kg}^{-1}$ intramuscularly), followed by an intravenous injection of pentobarbital sodium $\left(25 \mathrm{mg} \cdot \mathrm{kg}^{-1}\right)$. Animals were artificially ventilated with a volume-cycled respirator and maintained on $78.5 \%$ nitrous oxide, $20 \%$ oxygen, and $1.5 \%$ halothane inhalation anesthetics. An arterial catheter for the continuous measurement of blood radioactivity was inserted into the descending aorta via the right femoral artery. Another arterial catheter for measuring arterial blood pressure and for blood sampling was inserted into the abdominal aorta via the left femoral artery. A venous catheter was inserted via the right femoral vein for drug administrations. Core temperature was continuously monitored by a precalibrated thermistor placed in the cervical esophagus.

In 10 dogs with the $\mathrm{CPB}$ protocols, the chest was opened by a median sternotomy. After an intravenous administration of heparin sodium $(500 \mathrm{IU} / \mathrm{kg}$ intravenously), the left subclavian artery was cannulated retrogradely with a $16 \mathrm{~F}$ straight-type, polyvinyl chloride infusion cannula (PAA-016-SB; Research Medical, Inc., Midvale, Utah) for inflow. A two-staged venous drainage cannula (TF-1824-O; Research Medical) was inserted through the right atrial appendage into the inferior vena cava. The left ventricle was vented via the left atrium after $C P B$ had been established.

The bypass circuit consisted of a variable-volume venous reservoir (maximum volume, $800 \mathrm{ml}$ ), a roller pump (HAD 101; Mera, Tokyo, Japan), a membrane oxygenator-heat exchanger (Module 1500; Dideco, Mirandola, Italy), and an in-line arterial filter. Priming fluid consisted of $500 \mathrm{ml}$ of lactated Ringer's solution, $600 \mathrm{ml}$ of homologous blood, $100 \mathrm{ml}$ of $20 \%$ mannitol, $200 \mathrm{ml}$ of lowmolecular-weight dextran solution, $20 \mathrm{mEq}$ of sodium bicarbonatc, and $5000 \mathrm{IU}$ of heparin. About 30 minutes before $\mathrm{CPB}$, we discontinued halothane and nitrous oxide and switched the anesthesia to systemic administrations of fentanyl $\left(10 \mu \mathrm{g} \cdot \mathrm{kg}^{-1}\right.$ every 30 minutes), diazepam $(0.1$ $\mathrm{mg} \cdot \mathrm{kg}^{-1}$ every hour), and pancronium bromide $(0.1$ $\mathrm{mg} \cdot \mathrm{kg}^{-1}$ every 30 minutes). After the conclusion of CPB, we switched back to anesthesia with nitrous oxide and halothane. Arterial carbon dioxide tension was measured without temperature correction and maintained between 40 to $50 \mathrm{~mm} \mathrm{Hg}$ throughout the experiment. The temperature of the oxygenated blood from the oxygenator was continuously monitored with an in-line thermistor. The difference between the esophageal temperature and the blood temperature was kept within $5^{\circ} \mathrm{C}$ during CPB. During rewarming, no additional fluid was administered because this acutely decreased the blood radioactivity.

\section{Experimental protocols}

Measurement of $r C B F$ during hypothermic $C P B$. A blank scan was performed before the animals were placed on the scanner table. After the completion of surgical preparation, animals were positioned in the PET scanner (EXACT HR 47; Siemens AG-Bereich Medizinische Technik, Erlangen, Germany). The head of the animals were fixed so that their orbitomeatal line was parallel with the axis of the PET scanner. We instituted CPB at a flow rate of 60 $\mathrm{ml} \cdot \mathrm{kg}^{-1} \cdot \mathrm{min}^{-1}$, which was fixed until the end of the rewarming. The transmission images were obtained with a rotating rod source of ${ }^{68} \mathrm{Ga} /{ }^{68} \mathrm{Ge}$ in each animal to measure the photon attenuation and to correct the subsequent emission scans.

Protocol 1. We measured rCBF in five dogs during the cooling phase of hypothermic CPB. We infused ${ }^{15} \mathrm{O}$ labeled water $\left(2.0 \mathrm{mCi} \cdot 1.8 \mathrm{ml}\right.$ saline $\left.{ }^{-1} \cdot \min ^{-1}\right)$ continuously into the artery via the CPB circuit at a point $30 \mathrm{~cm}$ upstream from the tip of the arterial cannula after CPB was established. We withdrew arterial blood at a rate of 3 $\mathrm{ml} \cdot \mathrm{min}^{-1}$ for continuous measurements of blood radioactivity to obtain an arterial input function. After the radioactivity reached a steady state in both the arterial blood and the head, which usually took about 15 minutes, we acquired PET images at $37^{\circ} \mathrm{C}$ before cooling. Then the dogs were cooled to $20^{\circ} \mathrm{C}$. We acquired the PET images at $32^{\circ}, 28^{\circ}, 24^{\circ}$, and $20^{\circ} \mathrm{C}$ during cooling. This protocol was terminated after $\mathrm{rCBF}$ was measured at $20^{\circ} \mathrm{C}$ because of the hardware limitation of the cyclotron for producing radio-labeled water.

Protocol 2. To measure the $\mathrm{CCBF}$ during rewarming of $\mathrm{CPB}$ in another five dogs during the hypothermic CPB experiments, we first conducted hypothermic CPB and maintained the temperature at $20^{\circ} \mathrm{C}$ for 60 minutes. From 30 minutes before rewarming, we began to infuse ${ }^{15} \mathrm{O}$ labeled water $\left(2.0 \mathrm{mCi} \cdot 1.8 \mathrm{ml}\right.$ saline ${ }^{-1} \cdot$ min $\left.^{-1}\right)$ continuously into the artery via the CPB circuit. After the radioactivity reached a steady state in both the arterial blood and the head, we acquired PET images before rewarming. Then the dogs were rewarmed to $37^{\circ} \mathrm{C}$. During rewarming, we acquired PET images at $20^{\circ}, 24^{\circ}$, $28^{\circ}$, and $32^{\circ} \mathrm{C}$. When the esophageal temperature reached to $37^{\circ} \mathrm{C}$, the dogs were weaned from CPB. Then, ${ }^{15} \mathrm{O}$ -

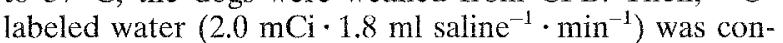
tinuously infused into the venous catheter placed in the 
Table I. Systemic physiologic variables during the cooling of hypothermic CPB

\begin{tabular}{lccccc}
\hline & \multicolumn{5}{c}{ Cooling phase of hypothermic CPB } \\
\hline Target temperature $\left({ }^{\circ} \mathrm{C}\right)$ & 37 & 32 & 28 & 24 & 20 \\
Measured temperature $\left({ }^{\circ} \mathrm{C}\right)$ & $36.4 \pm 0.5$ & $31.8 \pm 0.8$ & $28.2 \pm 0.5$ & $24.2 \pm 0.4$ & $19.4 \pm 0.2$ \\
Mean arterial pressure $(\mathrm{mm} \mathrm{Hg})$ & $77.2 \pm 12.8$ & $63.5 \pm 9.5^{*}$ & $64.3 \pm 5.2^{*}$ & $58.0 \pm 5.8^{*}$ & $59.4 \pm 10.8^{*}$ \\
$\mathrm{pH}$ & $7.28 \pm 0.11$ & $7.32 \pm 0.09$ & $7.33 \pm 0.32$ & $7.31 \pm 0.07$ & $7.30 \pm 0.06$ \\
$\mathrm{PaCO}_{2}(\mathrm{~mm} \mathrm{Hg})$ & $40.8 \pm 6.8$ & $48.9 \pm 10.3$ & $47.4 \pm 13.9$ & $46.6 \pm 10.6$ & $49.8 \pm 12.8$ \\
Blood hemoglobin concentration $\left(\mathrm{gm} \cdot \mathrm{dl}^{-1}\right)$ & $10.0 \pm 1.9$ & $9.3 \pm 1.5$ & $9.1 \pm 1.4^{*}$ & $9.1 \pm 1.4^{*}$ & $9.3 \pm 1.4$ \\
\hline
\end{tabular}

All values are expressed as mean \pm standard deviation: $n=5$. Blood $\mathrm{pH}$ and $\mathrm{PaCO}_{2}$ were measured without temperature correction. ${ }^{*} p<0.05$ versus the value before cooling.

inferior vena cava. After stabilization of the radioactivity, we acquired PET images at $37^{\circ} \mathrm{C}$.

Protocol 3. In another five dogs without CPB, we estimated control rCBF under halothane anesthesia with nitrous oxide by infusing ${ }^{15} \mathrm{O}$-labeled water $(2.0 \mathrm{mCi} \cdot 1.8$ $\mathrm{ml}$ saline $\mathrm{e}^{-1} \cdot \mathrm{min}^{-1}$ ) continuously into the venous catheter placed in the inferior vena cava.

Measurement of $r C M R_{g l c}$ To measure $\mathrm{rCMR}_{\mathrm{glc}},{ }^{18} \mathrm{FDG}$ $\left(0.9 \mathrm{mCi} \cdot \mathrm{kg}^{-1}\right)$ was injected via a femoral venous catheter. PET scanning was performed for 15 minutes from 45 minutes after the injection of ${ }^{18} \mathrm{FDG}$, according to the autoradiography method. ${ }^{13}$ We used halothane inhalation anesthesia with nitrous oxide during the measurement of $\mathrm{rCMR}_{\text {gic }}$ both after the weaning process from hypothermic CPB (protocol 2) and under the control condition (protocol 3). This was because of the necessity of metabolic stability during the measurement of $\mathrm{rCMR}_{\mathrm{glc}}$. With this anesthesia, brain function as judged by electroencephalography has been shown to be stable. ${ }^{14}$

After $\mathrm{rCMR}_{\mathrm{glc}}$ was measured in protocol 2, the descending aorta was clamped and $3 \mathrm{~L}$ of $10 \%$ formalin was infused into the arterial catheter for fixing the brain. The brain was taken out on the next day and was cut into $5 \mathrm{~mm}$ slices to examine the occurrence of cerebral hemorrhage and/or cerebral infarction.

Data analyses

Estimation of $r C B F$. Details of $\mathrm{rCBF}$ estimation with ${ }^{15} \mathrm{O}$-water have bcen described elsewhere. ${ }^{11}$ In brief, if we assume each sample volume consists of one compartment, mass-specific regional flow $(f)$ would be expressed as a function of brain radioactivity $\left(\chi \mathrm{mCi} \cdot \mathrm{gm}^{-1}\right)$ and arterial blood radioactivity $\left(C_{a} \mathrm{mCi} \cdot \mathrm{ml}^{-1}\right)$ as

$$
\frac{d X}{d t}=f C_{a}-\lambda X-\frac{f X}{V_{d}}
$$

where $V_{d}$ is the distribution volume for water (milliliters $\cdot$ grams $^{-1}$ ) and $\lambda$ is the decay constant for ${ }^{15} \mathrm{O}$. Under steady state conditions, $d X / d t$ is zero. Thus, $f$ can be derived from Equation 1 as

$$
f=\frac{\lambda X}{C_{a}-\frac{X}{V_{d}}}
$$

We used 0.774 as $V_{d}$ of the canine brain tissue. ${ }^{15}$ Because we measured both $C_{a}$ and $X$, we can determine $f$ with Equation 2.

To validate the assumption that $\mathrm{dX} / \mathrm{dt}$ is zero, we continuously monitored the radioactivity in both the arte- rial blood and the head. We confirmed, at each measurement, that the input radioactivity remained constant. This confirmation was also done at a time of data analysis.

Estimation of $r C M R_{g l c}$. Details of $\mathrm{rCMR}_{\mathrm{glc}}$ estimation with ${ }^{18} \mathrm{FDG}$ have been described elsewhere. ${ }^{11}$ In brief, ${ }^{18}$ FDG entered the brain tissues would be trapped as ${ }^{18}$ FDG-6-phosphate by hexokinase phospholylation. This process is considered to quantify glucose use. In this investigation, we used a three-compartment model. ${ }^{13,16}$ We adopted the rate constants $k_{1}, k_{2}, k_{3}$, and $k_{4}{ }^{17}$ and lumped constant ${ }^{15}$ from literature. With the measurements of brain radioactivity $X$ and arterial blood radioactivity $C_{a}$ as an input function, one can derive rCMR $_{\text {glc }}{ }^{15}$

The best spatial resolution of the PET scanner (ECAT EXACT HR 47) ${ }^{18}$ at full-width half-maximum was $3.6 \mathrm{~mm}$ in the center of the scan field of the cross plane, with 784 crystals per ring. This scanner had 24 rings and could obtain 47 slices simultaneously. The plane spacing was $3.125 \mathrm{~mm}$. We reconstructed a functional image consisting of $128 \times 128$ pixels, with each pixel measuring $0.875 \times$ $0.875 \mathrm{~mm}$. For the sake of convenience, we derived rCBF and $\mathrm{rCMR}_{\mathrm{glc}}$ of the frontal cortex, parietal cortex, temporal cortex, and basal ganglia to set a circular region of interest in each region.

Statistics. All data were expressed as mean \pm one standard deviation. Changes in rCBF and physiologic variables during cooling and rewarming were tested by two-way analysis of variance with repeated measures (factor: temperature and rCBF or physiologic variables) followed by Dunnet's multiple comparison test. ${ }^{19}$ The inhomogeneity of $\mathrm{rCBF}$ and $\mathrm{rCMR}_{\mathrm{glc}}$ among the four brain regions at each temperature was tested by two-way analysis of variance with repeated measures (factor: each animal and region). ${ }^{19}$ The difference between the two groups was tested by Mann-Whitney test. ${ }^{19}$

\section{Results}

There was no obvious hemorrhage or infarction in the brain after the end of the rewarming experiment $(n=5)$.

Changes of $\mathrm{rCBF}$ during the cooling phase of hypothermic $\mathbf{C P B}$. In the cooling experiment, core temperature was cooled to $20^{\circ} \mathrm{C}$ in $55.0 \pm 10.6$ minutes. Systemic physiologic variables during cooling are summarized in Table I. Mean arterial pressure significantly decreased at temperatures below $28^{\circ} \mathrm{C}$. Blood hemoglobin concentration was signifi- 


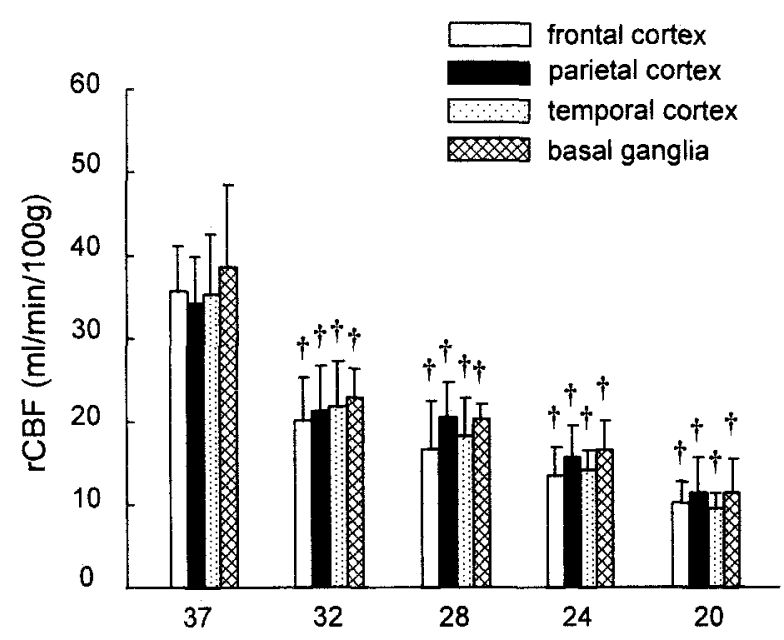

Esophageal Temperature during $\mathrm{CPB}\left({ }^{\circ} \mathrm{C}\right)$

Fig. 1. Changes in $\mathrm{rCBF}$ in the frontal cortex, parietal cortex, temporal cortex, and basal ganglia during cooling. The rCBF decreases with decreases in temperature. There were no interregional differences throughout cooling. Values are expressed as mean \pm one standard deviation. $\uparrow p<0.05$, compared with $\mathrm{rCBF}$ at $37^{\circ} \mathrm{C}$ before cooling.

cantly lower during cooling than in the control. Neither arterial $\mathrm{pH}$ nor carbon dioxide tension significantly changed during cooling.

The pooled data of rCBF during cooling are shown in Fig. 1. Cooling significantly decreased $\mathrm{rCBF}$ in all regions. At $28^{\circ} \mathrm{C}$, rCBFs were nearly halved. At $20^{\circ} \mathrm{C}, \mathrm{rCBFs}$ were approximately one fourth of their control values. Although the changes in $\mathrm{rCBF}$ in the parietal cortex tended to delay compared with those in other regions, there was no significant interregional difference among the regions.

Changes of $\mathrm{rCBF}$ during the rewarming phase of hypothermic CPB $(\boldsymbol{n}=5)$. The total CPB time was $170.1 \pm 10.2$ minutes. The cooling and the rewarming were achieved in $53.3 \pm 6.8$ minutes and $57.0 \pm$ 5.7 minutes, respectively. Physiologic variables during rewarming are summarized in Table II. Arterial pressure increased with rewarming. It significantly increased at temperatures above $32^{\circ} \mathrm{C}$ compared with that at $20^{\circ} \mathrm{C}$. Blood hemoglobin concentration increased with rewarming. Blood hemoglobin concentrations at $32^{\circ}$ and $37^{\circ} \mathrm{C}$ were significantly higher than those before rewarming. Both arterial $\mathrm{pH}$ and carbon dioxide tension remained unchanged during rewarming.

The pooled data of $\mathrm{rCBF}$ during rewarming, which increased $\mathrm{rCBF}$ in all regions, are shown in
Fig. 2, A. However, at $28^{\circ} \mathrm{C}$, rCBF in the parietal cortex still did not significantly differ from that before rewarming, although $\mathrm{rCBF}$ in other regions were significantly higher than those before rewarming. At $24^{\circ}, 28^{\circ}$, and $32^{\circ} \mathrm{C}$, two-way analysis of variance indicated the significant regional difference in $\mathrm{rCBF}(p=0.0075,0.034$, and 0.048 , respectively). At the end of rewarming, this inhomogeneity of rCBF disappeared. rCBF after rewarming did not significantly differ from that at $37^{\circ} \mathrm{C}$ in the control group with anesthesia and without CPB (protocol 3; Fig. 2, $B$ ).

Effects of hypothermic CPB on posthypothermic rCMR $_{\text {glc }}$. Physiologic variables at the measurement of rCMR $_{\mathrm{glc}}$ are summarized in Table III. Esophageal temperature, arterial pressure, blood glucose concentration, arterial oxygen tension, and arterial carbon dioxide tension were not significantly different between the groups. Blood hemoglobin concentration was significantly lower in the CPB group $(p<0.05)$.

The $\mathrm{rCMR}_{\mathrm{glc}}$ in the control condition without hypothermic CPB and after weaning from hypothermic CPB is shown in Fig. 3. There was no interregional difference in $\mathrm{rCMR}_{\mathrm{glc}}$ in the control condition. However, after the weaning process from CPB, there was a significant interregional difference in $\mathrm{rCMR}_{\mathrm{glc}}(p=0.010)$. The relation between $\mathrm{rCBF}$ and $\mathrm{rCMR}_{\mathrm{glc}}$ without $\mathrm{CPB}$ and after $\mathrm{CPB}$ at $37^{\circ} \mathrm{C}$ is shown in Fig. 4. The rCBF and $\mathrm{rCMR}_{\text {glc }}$ were tightly coupled without CPB (Fig. 4, $A$ ). The tight coupling disappeared after CPB (Fig. 4, $B$ ). Instead, posthypothermic $\mathrm{rCMR}_{\mathrm{glc}}$ significantly correlated with $\mathrm{rCBF}$ during rewarming, especially that at $32^{\circ} \mathrm{C}$ (Fig. 5).

\section{Discussion}

We investigated the changes in $\mathrm{rCBF}$ during hypothermic CPB and those in $\mathrm{rCMR}_{\text {glc }}$ after hypothermic CPB. We have shown that there was a significant interregional difference in the recovery of rCBF during rewarming. The rCBF during rewarming significantly correlated with posthypothermic $\mathrm{rCMR}_{\mathrm{glc}}$. The close correlation between $\mathrm{rCBF}$ and $\mathrm{rCMR}_{\mathrm{glc}}$ disappeared after profoundly hypothermic CPB.

Mechanism of the inhomogeneity of rCBF during rewarming. During rewarming, significant interregional differences in rCBF were observed at $24^{\circ}, 28^{\circ}$, and $32^{\circ} \mathrm{C}$ (Fig. 2). Because rCBF is closely coupled with regional $\mathrm{CMRO}_{2},{ }^{20}$ which was the case in the control condition without CPB (Fig. 4, A), it is 


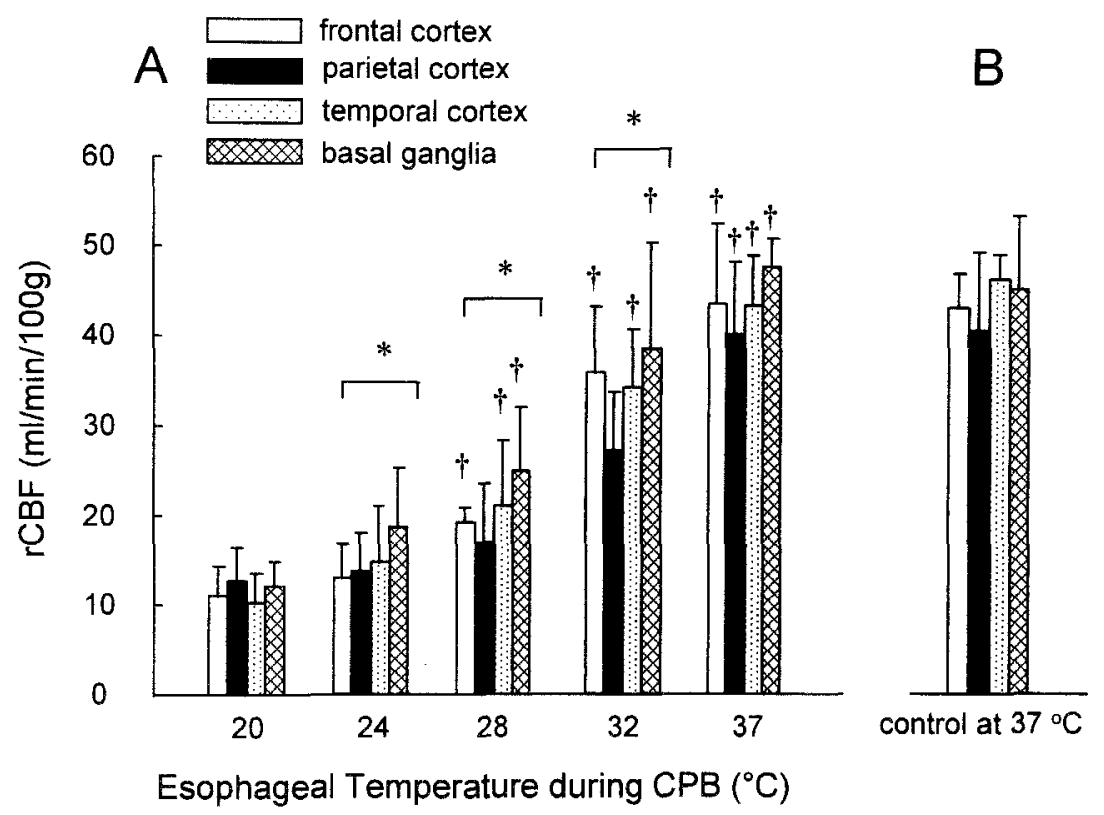

Fig. 2. A, Changes in rCBF during rewarming. At $24^{\circ}, 28^{\circ}$, and $32^{\circ} \mathrm{C}$, two-way analysis of variance with repeated measures showed significant differences among the regions. Values are expressed as mean \pm one standard deviation. $t p<0.05$ compared with $\mathrm{rCBF}$ before rewarming. "Significant interregional difference $(p<0.05)$. B, The rCBF at $37^{\circ} \mathrm{C}$ without $\mathrm{CPB}$. There was no interregional difference in $\mathrm{rCBF}$.

Table II. Physiologic variables during the rewarming of hypothermic CPB

\begin{tabular}{|c|c|c|c|c|c|}
\hline \multirow[b]{2}{*}{ Target temperature $\left({ }^{\circ} \mathrm{C}\right)$} & \multicolumn{5}{|c|}{ Rewarming phase of hypothermic CPB } \\
\hline & 20 & 24 & 28 & 32 & 37 \\
\hline Measured temperature $\left({ }^{\circ} \mathrm{C}\right)$ & $19.7 \pm 0.2$ & $24.2 \pm 0.4$ & $28.2 \pm 0.4$ & $31.6 \pm 0.9$ & $36.8 \pm 0.5$ \\
\hline Mean arterial pressure (mm $\mathbf{H g}$ ) & $55.9 \pm 9.4$ & $63.2 \pm 15.2$ & $65.4 \pm 15.2$ & $70.8 \pm 14.0^{*}$ & $86.7 \pm 12.9^{*}$ \\
\hline $\mathrm{pH}$ & $7.28 \pm 0.11$ & $7.29 \pm 0.07$ & $7.29 \pm 0.09$ & $7.30 \pm 0.06$ & $7.30 \pm 0.06$ \\
\hline $\mathrm{PaCO}_{2}(\mathrm{~mm} \mathrm{Hg})$ & $51.0 \pm 10.4$ & $46.4 \pm 5.7$ & $47.9 \pm 7.7$ & $46.8 \pm 11.1$ & $46.9 \pm 9.7$ \\
\hline Blood hemoglobin concentration $\left(\mathrm{gm} \cdot \mathrm{al}^{-1}\right)$ & $9.8 \pm 1.4$ & $9.9 \pm 1.1$ & $10.0 \pm 0.9$ & $10.3 \pm 0.9^{*}$ & $11.1 \pm 1.6^{*}$ \\
\hline
\end{tabular}

All values are expressed as mean \pm standard deviation: $n=5$. Blood $\mathrm{pH}$ and $\mathrm{PaCO}_{2}$ were measured without temperature correction. ${ }^{*} p<0.05$ versus the value before rewarming.

conceivable that the inhomogeneity of $\mathrm{rCBF}$ during rewarming reflected that of cerebral metabolism. Although we did not observe the inhomogeneity of rCBF at any time during the cooling (Fig. 1), the regional difference in the brain temperature during rewarming ${ }^{21}$ might vary the $\mathrm{rCBF}$. The regional difference in the recovery of the brain function might also affect the $\mathrm{rCBF}$ during the rewarming without the regional difference in temperature. However, the disappearance of the tight relation between $\mathrm{rCBF}$ and $\mathrm{rCMR}_{\mathrm{glc}}$ after hypothermic CPB (Fig. $4, B$ ) and the close relation between rCBF at $32^{\circ} \mathrm{C}$ and $\mathrm{rCMR}_{\mathrm{glc}}$ after CPB (Fig. 5) suggest that the inhomogeneity of $\mathrm{rCBF}$ might be a manifestation of the loss of temperature-coupled or functioncoupled regulation of $\mathrm{rCBF}$.
The long-lasting hypothermia might alter the regional cerebral vascular response. This might explain why the inhomogeneity of $\mathrm{rCBF}$ did not occur during cooling. The microemboli of air, fat, or particulate materials derived from aortic atheroma $3-7,22$ might also be responsible for the observed changes in the rCBF during rewarming. Because we chose the left subclavian root for arterial cannulation and did not clamp the aorta, the particulate materials from the aortic root might not be responsible for microembolization. Instead, gaseous emboli might be a candidate for microembolization during hypothermic CPB in our experiment. In fact, Johnston and associates ${ }^{22}$ have shown significant gaseous emboli even with the use of the membrane oxygenator and arterial filter in dogs. 


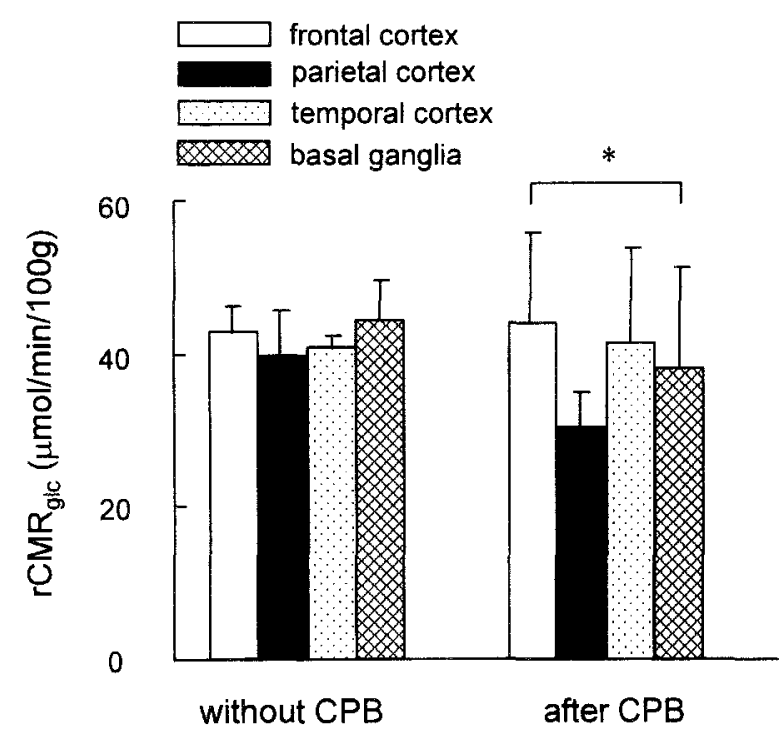

Fig. 3. $\mathrm{rCMR}_{\mathrm{glc}}$ with the use of halothane anesthesia with nitrous oxide without CPB (left) and after being weaned from hypothermic CPB (right). There was no interregional difference in $\mathrm{rCMR}_{\mathrm{glc}}$ without $\mathrm{CPB}$. However, a significant interregional difference was observed after hypothermic CPB by two-way analysis of variance with repeated measures. Values are expressed as mean \pm one standard deviation. ${ }^{*} p=0.010$.

Although we cannot clearly determine which factor is primarily responsible for the observed changes in $\mathrm{rCBF}$, the close correlation between $\mathrm{rCBF}$ at $32^{\circ} \mathrm{C}$ and $\mathrm{rCMR}_{\mathrm{glc}}$ after $\mathrm{CPB}$ suggests that $\mathrm{rCBF}$ during rewarming might affect brain metabolism after CPB.

rCBF during rewarming as a possible determinant of rCMR $_{\text {gle }}$ after CPB. The flow-metabolic decoupling during rewarming might be responsible for rCMR $_{\mathrm{glc}}$ after CPB. Markand and associates ${ }^{23}$ showed the temperature-dependent hysteresis in cortical-evoked potentials. They showed the initial exaggerated response of cortical-evoked potential latencies at the onset of rewarming. ${ }^{23}$ On the contrary, the recovery in $\mathrm{rCBF}$ in our experiment was slow and became prominent above $28^{\circ} \mathrm{C}$ (Fig. 2, $A$ ). Thus it is conceivable that $\mathrm{rCBF}$ for brain metabolism during rewarming may not be sufficient and thereby affects $\mathrm{rCMR}_{\text {glc }}$ after CPB.

Several investigations have shown that hypothermic CPB did not affect cerebral energy production $^{9,10,22}$ or global $\mathrm{CMRO}_{2} .{ }^{8-10}$ These results indicated that aerobic glycolysis remained unimpaired. The discrepancy between those results and ours might be explained in part by the uncoupling be-
Table III. Physiologic variables at the time of $r C M R_{g l c}$ measurement under control conditions and after being weaned from hypothermic $C P B$

\begin{tabular}{lll}
\hline & \multicolumn{1}{c}{ Control } & After $\mathrm{CPB}$ \\
\hline Core temperature $\left({ }^{\circ} \mathrm{C}\right)$ & $36.4 \pm 0.5$ & $36.8 \pm 0.7$ \\
Mean arterial pressure $(\mathrm{mm} \mathrm{Hg})$ & $86.3 \pm 3.9$ & $82.2 \pm 7.8$ \\
$\mathrm{pH}$ & $7.33 \pm 0.15$ & $7.35 \pm 0.22$ \\
$\mathrm{PaCO}_{2}(\mathrm{~mm} \mathrm{Hg})$ & $41.3 \pm 5.6$ & $43.2 \pm 8.8$ \\
$\mathrm{PaO}_{2}(\mathrm{~mm} \mathrm{Hg})$ & $85.6 \pm 3.2$ & $82.1 \pm 4.1$ \\
$\mathrm{Blood}_{\mathrm{alucose}}\left(\mathrm{mg} \cdot \mathrm{dl}^{-1}\right)$ & $69.2 \pm 5.1$ & $75.4 \pm 8.4$ \\
$\mathrm{Blood}$ hemoglobin concentration & $14.8 \pm 1.4$ & $12.2 \pm 1.3^{*}$ \\
$\quad\left(\mathrm{gm} \cdot \mathrm{dl}{ }^{-1}\right)$ & & \\
\hline All values are mean \pm standard deviation: $n=5 .{ }^{*} p<0.05$ versus control.
\end{tabular}

tween $\mathrm{CMRO}_{2}$ and $\mathrm{rCMR}_{\mathrm{glc}}$, which has been shown to occur in acute cerebral ischemia. ${ }^{24-26}$ Alternatively, there is also a possibility that the global measurement of the brain metabolism in the previous studies might not be sensitive enough to reflect these regional metabolic changes. Therefore our results suggest that profoundly hypothermic CPB may alter both $\mathrm{rCBF}$ and metabolism, although the precise mechanism remains to be elucidated.

Neurologic implications of the reduced $\mathrm{rCMR}_{\mathrm{glc}}$ detected by PET. In patients who have experienced stroke, Heiss and associates ${ }^{25}$ reported that the increase in $\mathrm{rCMR}_{\mathrm{glc}}$ paralleled a significant clinical improvement. This observation supports the notion that regional decreases in glucose use indicate the functional depression in the corresponding regions. On the other hand, Powers and associates ${ }^{27}$ showed that $\mathrm{CMRO}_{2}$ under normal central nervous system function has some degree of variability. Because it was impossible to perform the neurologic examination after hypothermic CPB in our experimental setting, it is not clear whether the observed change in $\mathrm{rCMR}_{\mathrm{glc}}$ correlates with the change in brain function. However, the fact that a certain percentage of patients experience neuropsychologic dysfunction after hypothermic CPB, even though most of the neuropsychologic dysfunctions are subtle and transient, ${ }^{1-3}$ might support our results that show a pathologic implication of profoundly hypothermic CPB. Further investigations are required to clarify the relation between the altered brain glucose metabolism induced by hypothermic CPB and neuropsychologic function.

Methodologic considerations. The prolonged cerebral hypoperfusion during $\mathrm{CPB}$ has been thought to affect $\mathrm{rCMR}_{\mathrm{glc}}$ after $\mathrm{CPB} .^{3}$ In our experiments, mean arterial blood pressure was above $55 \mathrm{~mm} \mathrm{Hg}$ at $20^{\circ} \mathrm{C}$, and it was always above $60 \mathrm{~mm} \mathrm{Hg}$ during rewarming. Swain and associates ${ }^{28}$ have shown that 


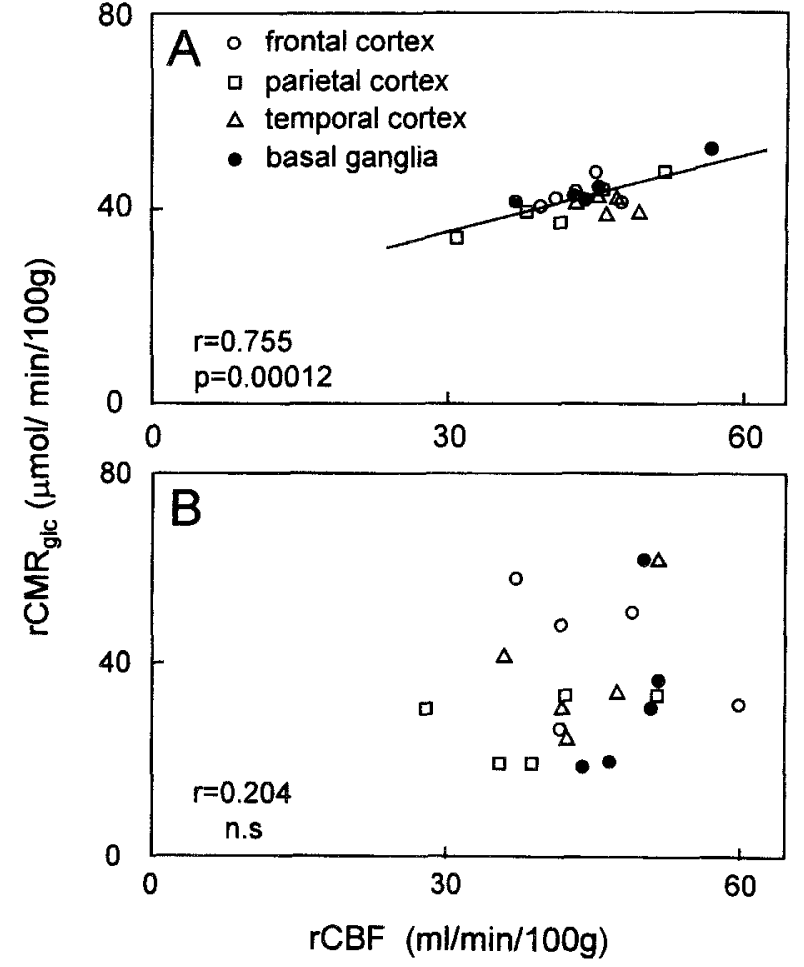

Fig. 4. Correlation between $\mathrm{rCBF}$ and $\mathrm{rCMR}_{\mathrm{glc}}$ in the control condition without $\mathrm{CPB}$ (A) and after being weaned from hypothermic CPB (B). Although there was a significant positive correlation between $\mathrm{rCBF}$ and $\mathrm{rCMR}_{\mathrm{glc}}$ in the control condition, this significant correlation disappeared after profoundly hypothermic CPB.

cerebral perfusion at a rate of $10 \mathrm{ml} / \mathrm{kg}$ per minute, with mean arterial pressure ranging from 40 to 50 $\mathrm{mm} \mathrm{Hg}$ at $15^{\circ} \mathrm{C}$, preserved brain high-energy phosphate in sheep. Also in human children, Greeley and associates $^{8}$ reported that mean arterial pressure even below $60 \mathrm{~mm} \mathrm{Hg}$ during deep hypothermia and rewarming did not affect oxygen metabolism after CPB. Although these earlier studies suggest that mean arterial pressure in this study would be high enough not to significantly affect $\mathrm{rCBF}$ or $\mathrm{rCMR}_{\mathrm{glc}}$, there is still a possibility that global measurements of cerebral blood flow and metabolism ${ }^{8,28}$ could not reflect their regional changes. It is worthy of further investigation to examine whether or not arterial pressure during hypothermic $\mathrm{CPB}$ affects $\mathrm{rCBF}$ and regional metabolism.

We used the combination of fentanyl and diazepam as anesthetics during CPB. Although fentanyl has been shown to not significantly affect $\mathrm{CBF}$ in dogs, ${ }^{29}$ diazepam might affect $\mathrm{rCMR}_{\mathrm{glc}}$ after hypothermic CPB. However, it does not explain the

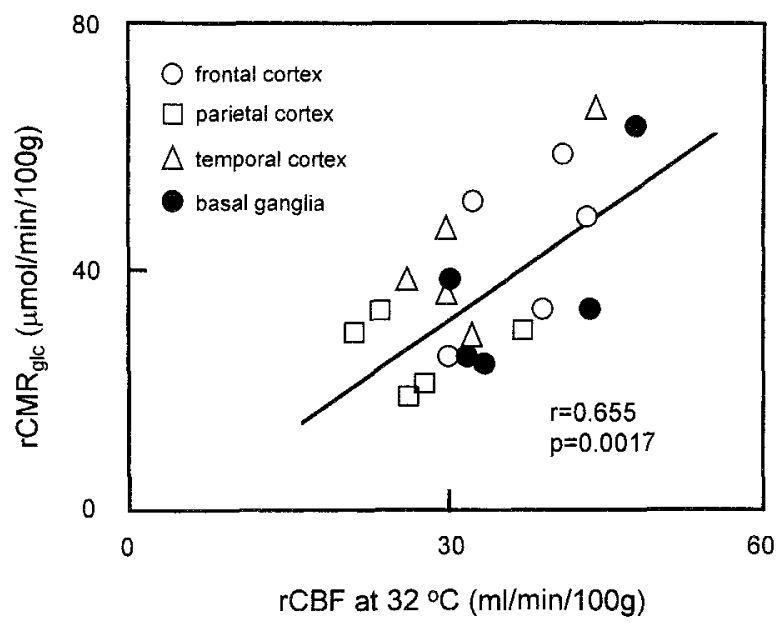

Fig. 5. Significant positive correlation between rCBF at $32^{\circ} \mathrm{C}$ during rewarming and $\mathrm{rCMR}_{\mathrm{glc}}$ after weaning from profoundly hypothermic CPB.

inhomogeneity of $\mathrm{rCBF}$ during rewarming, nor does it explain the interregional difference in $\mathrm{rCMR}_{\mathrm{glc}}$. Both nitrous oxide and halothane have been reported to increase the $\mathrm{CBF}^{14,30}$ and $\mathrm{CBF} / \mathrm{CMRO}_{2}$ ratio in human beings. ${ }^{14}$ However, the fact that rCBF closely correlated with $\mathrm{rCMR}_{\text {glc }}$ in our study (Fig. 4, $A$ ) might indicate the combination of nitrous oxide and halothane little affected the cerebral flow-metabolic coupling.

We assumed that the distribution volume of the cerebral cortex did not alter during hypothermic CPB. Although it has been reported that the changes in brain water content, such as brain edema, may change the distribution volume, this change has been thought to be significant in the white matter rather than in the gray matter. ${ }^{11}$ Therefore the changes in the distribution volume may not significantly affect our estimation of rCBF. We also assumed that the rate constant and the lumped constant of ${ }^{18} \mathrm{FDG}$ did not change after hypothermic $\mathrm{CPB}$. Because we used the autoradiography method, the changes in the rate constant might not significantly affect our estimation of $\mathrm{rCMR}_{\mathrm{glc}}{ }^{11}$ However, because the lumped constant has been shown to vary in certain pathological states, ${ }^{11}$ there is a possibility that the changes in the lumped constant might affect our estimation of $\mathrm{rCMR}_{\text {gic }}$ after rewarming.

In summary, we have shown a possibility that rCBF during rewarming might affect the cerebral metabolism after hypothermic CPB. However, because of the small number of the animals used in this study, further investigations are mandatory to 
establish the regional flow-metabolism relation during and after profoundly hypothermic CBP.

This study was prepared in consultation with a statistician, Masaru Sugimachi, MD.

\section{REFERENCES}

1. Shaw PJ, Bates D, Cartridge NEF, French JM, Heaviside D, Julian DG, et al. Neurologic and neuropsychological morbidity following major surgery: comparison of coronary artery bypass and peripheral vascular surgery. Stroke 1987;18:700-7.

2. Heyer EJ, Delphin E, Adams DC, Rose EA, Smith CR, Todd GJ, et al. Cerebral dysfunction after cardiac operations in the elderly patients. Ann Thorac Surg 1995;60:1716-22.

3. Smith PL, Treasure T, Newman SP, Joseph P, Ell P, Schneidau A, et al. Cerebral consequences of cardiopulmonary bypass. Lancet 1986;12:823-5.

4. Harrison MJG, Pugsley W, Newman S, Paschalis C, Klinger L, Treasure T, et al. Detection of middle cerebral emboli during coronary artery bypass surgery using transcranial doppler sonography [letter]. Stroke 1990;21:1512.

5. Blauth CI, Smith PL, Jagoe JR, Wootton R, Taylor KM. Influence of oxygenator type on the prevalence and extent of microembolic retinal ischemia during cardiopulmonary bypass: assessment by digital image analysis. J Thorac Cardiovasc Surg 1990;99:61-9.

6. Moody DM, Bell MA, Challia VR, Johnston WE, Prough DS. Brain microemboli during cardiac surgery or aortography. Ann Neurol 1990:28:477-86.

7. Barbut D, Yao FS, Hager DN, Kavanaugh P, Trifiletti RR, Gold JP. Comparison of transcranial Doppler ultrasonography and transesophageal echocardiography to monitor emboli during coronary artery bypass surgery. Stroke 1996;27:87-90.

8. Greeley WJ, Kcrn FH, Ungerleider RM, Boyd JL III, Quill T, Smith LR, ct al. The effect of hypothermic cardiopulmonary bypass and total circulatory arrest on cerebral metabolism in neonates, infants, and children. J Thorac Cardiovasc Surg 1991;101:783-94.

9. Michenfelder JD, Milde JH. The relationship among canine brain temperaturc, metabolism, and function during hypothermia. Anesthesiology 1991;75:130-6.

10. Michenfelder JD, Milde JH. The effects of profound hypothermia (below $14^{\circ} \mathrm{C}$ ) on canine cerebral metabolism. J Cereb Blood Flow Metab 1992;12:877-80.

11. Baron JC, Frackowiak RSJ, Herholz K, Jones T, Lammertsma AA, Mazoyer B, et al. Use of PET methods for measurement of cerebral energy metabolism and hemodynamics in cerebrovascular disease. $\mathrm{J}$ Cereb Blood Flow Metab 1989;9:723-42.

12. Ganzel BL, Edmonds HL, Pank JR, Goldsmith LJ. Neurophysiologic monitoring to assure delivery of retrograde cerebral perfusion. J Thorac Cardiovasc Surg 1997;113:748-57.

13. Anderson JH, Strandberg JD, Wong DF, Conti PS, Barker $\mathrm{PB}$, Blackband SJ, et al. Multimodality correlatives study of canine brain tumors--proton resonance spectroscopy, positron emission tomography and histology. Invest Radiol 1994:29:597-605.

14. Kuroda Y, Murakami M, Tsuruta J, Murakawa T, Sakabe T. Preservation of the ratio of cerebral blood flow/metabolic rate for oxygen during prolonged anesthesia with isoflurane, sevoflurane, and halothane in humans. Anesthesiology 1996; 84:555-61.

15. Sokoloff L, Reivich M, Kennedy C, des Rosiers MH, Patlak $\mathrm{CS}$, Pettgnew KD, et al. The $14 \mathrm{C}$ deoxyglucose method for the measurement of local cerebral glucose utilization: theory, procedure and normal values in the conscious and anesthetized albino rat. J Neurochem 1977;28:897-916.

16. Phelps KF, Huang SC, Hoffman FJ, Sokoloff L, Kuhl DF. Tomographic measurement of local cerebral glucose metabolic rate in human with (F-18) 2-fluoro-2-deoxy-D-glucose: validation of method. Ann Rev Neurol 1979;6:371-88.

17. Hawkins R, Phelps M, Huang S. Effects of temporal sampling, glucose metabolic rates and disruptions of the bloodbrain barrier on FDG model with and without a vascular compartment. J Cereb Blood Flow Metab 1986;6:170-83.

18. Wienhard K, Dahlbom M, Eriksson L, Michel C, Bruckbauer T, Pietrzyk U, et al. The ECAT EXACT HR: performance of a new high resolution positron scanner. J Comput Assist Tomogr 1994;18:110-8.

19. Glantz SA. Primer of biostatistics. 3rd edition. New York: McGraw-Hill; 1992. p. 278-363.

20. Scitz RJ, Roland PE. Vibratory stimulation increases and decreases the regional cerebral blood flow and oxidative metabolism: a positron emission tomography (PET) study. Acta Neurol Scand 1992;86:60-7.

21. Stone JG, Young WL, Smith CR, Solomon RA, Wald A, Ostapkovich N, et al. Do standard monitoring sites reflect true brain temperature when profound hypothermia is rapidly induced and reversed? Anesthesiology 1995;82:344-51.

22. Johnston WE, Stump DA, DeWitt DS, Vinten-Johansen J, O'Stcen WK, James RL, et al. Significance of gaseous microcmboli in the cerebral circulation during cardiopulmonary bypass in dogs. Circulation 1993;88(Suppl):I1319-29.

23. Markand ON, Warren C, Mallick GS, Williams CJ. Temperaturc-dependent hysteresis in somatosensory and auditory cvoked potentials. Electroencephalogr Clin Neurophysiol 1990;77:425-35.

24. Wisc RJS, Rhodes CG, Gibbs JM, Hatazawa J, Palmer T, Frackowiak RSJ, et al. Disturbance of oxidative metabolism of glucose in recent human cerebral infarcts. Ann Neurol 1983;14:627-37.

25. Heiss WD, Huber M, Fink GR, Herholz K, Pietrzyk U, Wagner $R$, et al. Progressive derangement of periinfaret viable tissue in ischemic stroke. J Cereb Blood Flow Metab 1992;12:193-203.

26. Synder J, Nemoto EM, Carroll RG, Safar P. Global ischemia in dogs: intracranial pressures, brain blood flow and metabolism. Stroke 1975;6:21-7.

27. Powers WJ, Grubb RLJ, Darriet D, Raichle ME. Cerebral blood flow and ecrebral metabolic rate of oxygen requirements for cerebral function and viability in humans. $\mathrm{J}$ Ccreb Blood Flow Metab 1985;5:600-8.

28. Swain JA, McDonald TJ, Griffith PK, Balaban RS, Clark RE, Ceckler T. Low-flow hypothermic cardiopulmonary bypass protects the brain. J Thorac Cardiovasc Surg 1991;102:76-84.

29. Milde LN, Milde JH, Gallagher WJ. Cerebral effects of fentanyl in dogs. Br J Anaesth 1989;63:710-5.

30. Reinstrup P, Ryding E, Algotsson L, Berntman L, Uski T. Effects of nitrous oxide on human regional cerebral blood flow and isolated pial arteries. Anesthesiology 1994;81:396402. 